\title{
Biochemical characterization of a catalase from Vibrio vulnificus, a pathogen that causes gastroenteritis
}

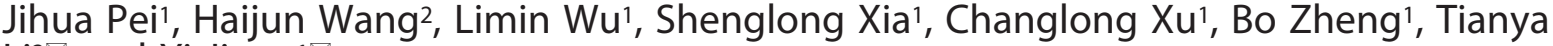 \\ $\mathrm{Li}^{2 \bowtie}$ and $\mathrm{Yi}$ Jiang ${ }^{1 凶}$
}

1Department of Gastroenterology, The second Affiliated Hospital of Wenzhou Medical University, Wenzhou 325027, Zhejiang, China; ${ }^{2}$ College of Plant Protection, Shenyang Agricultural University, Shenyang 110866, Liaoning, China

\begin{abstract}
Vibrio vulnificus is a virulent human pathogen causing gastroenteritis and possibly life threatening septicemia in patients. Most $V$. vulnificus are catalase positive and can deactivate peroxides, thus allowing them to survive within the host. In the study presented here, a catalase from V. vulnificus (CAT-Vv) was purified to homogeneity after expression in Escherichia coli. The kinetics and function of CAT-Vv were examined. CAT-Vv catalyzed the reduction of $\mathrm{H}_{2} \mathrm{O}_{2}$ at an optimal $\mathrm{pH}$ of 7.5 and temperature of $35^{\circ} \mathrm{C}$. The $V_{\max }$ and $K_{\mathrm{m}}$ values were $65.8 \pm 1.2 \mathrm{U} / \mathrm{mg}$ and 10.5 $\pm 0.7 \mathrm{mM}$ for $\mathrm{H}_{2} \mathrm{O}_{2}$, respectively. Mutational analysis suggests that amino acids involved in heme binding play a key role in the catalysis. Quantitative reverse transcription-PCR revealed that in $V$. vulnificus, transcription of $C A T-V V$ was upregulated by low salinity, heat, and oxidative stresses. This research gives new clues to help inhibit the growth of, and infection by $V$. vulnificus.
\end{abstract}

Key words: catalase, Vibrio vulnificus, kinetics, mutation, gastroenteritis.

Received: 22 February, 2017; revised: 24 April, 2017; accepted: 24 April, 2017; available on-line: 12 September, 2017

e-mail: litianya11@163.com (TL); yijiang1970@gmail.com (YJ) Abbreviations: V. vulnificus, Vibrio vulnificus; CAT-Vv, catalase from V. vulnificus

\section{INTRODUCTION}

Vibrio vulnificus is a Gram-negative marine bacterium that grows in warm water and low salinity in coastal regions (Kitamura et al., 2016; Motes et al., 1998); it survives in a planktonic form associated with the mucosal surfaces of aquatic animals (Oliver, 2015; Pajuelo et al., 2016). Wound infection or oral infection result from exposure to seawater or from the handling of shellfish contaminated with $V$. vulnificus, generally causing mild gastroenteritis with diarrhea, vomiting, and abdominal pain (Chung et al., 2016; Strom \& Paranjpye, 2000). However, $V$. vulnificus in the human gut can cause life-threatening septicemia when it crosses the intestinal mucosal barrier and enters the bloodstream (Lee et al., 2008). Over 90\% of infections resulting in septicemia from $V$. vulnificus are associated with consumption of raw and/or undercooked oysters (Oliver, 2015). Therefore, efforts have been made to eliminate $V$. vulnificus in postharvest processing of oysters, including cool pasteurization (Melody et al., 2008), inactivation by high hydrostatic pressure (Ye et al., 2013), irradiation (Mahmoud, 2009), and treatment with sodium hypochlorite (Ramos et al., 2012).

Catalase [hydrogen-peroxide:hydrogen-peroxide oxidoreductase (EC 1.11.1.6)], which specifically catalyzes the decomposition of $\mathrm{H}_{2} \mathrm{O}_{2}$ to $\mathrm{H}_{2} \mathrm{O}$ and $\mathrm{O}_{2}$, is present in animals, plants, fungi, most aerobic bacteria and some anaerobic bacteria. The reaction catalyzed by catalase is very fast (reaction rate constant $K \approx 10^{7} \mathrm{M}^{-1} \times \mathrm{s}^{-1}$ ) (Deisseroth \& Dounce, 1970). When the concentration of $\mathrm{H}_{2} \mathrm{O}_{2}$ is low $\left(<10^{-6} \mathrm{M}\right)$, catalase works in a peroxidatic mode, where it can oxidize many hydrogen donors (e.g., ethanol, ascorbic acid, phenols, formaldehyde). At high concentrations of $\mathrm{H}_{2} \mathrm{O}_{2}\left(>10^{-6}\right)$, it works "catalytically," where $\mathrm{H}_{2} \mathrm{O}_{2}$ acts as both, the acceptor and donor of hydrogen (Anjum et al., 2016). Depending on their physical and biochemical characteristics, catalases can be divided into four types: monofunctional heme catalases, catalaseperoxidases, non-heme catalases, and minor catalases (Sooch et al., 2014). Catalase is a significant component of cellular defense systems against oxidative stress that maintain reactive oxygen species, which are formed as byproducts of different metabolic reactions, at appropriate steady-state levels (Foyer \& Noctor, 2000; Mullineaux et al., 2006). Catalase also plays an important role in signal perception (Lushchak, 2015).

Catalase activity protects bacteria from disinfection by hydrogen peroxide, which is used in hospitals to clean surfaces. Nakamura et al. had shown that microbial catalase suppresses generation of hydroxyl radicals in a disinfection system in which hydroxyl radicals are artificially generated by photolysis of $\mathrm{H}_{2} \mathrm{O}_{2}$ (Nakamura et al., 2012). Catalase also plays a protective role against UVA radiation in both, planktonic cells and biofilms of Pseudomonas aeruginosa, a versatile bacterium present in terrestrial and aquatic environments and an important opportunistic pathogen of humans (Pezzoni et al., 2014). Therefore, it is possible that inactivation of catalase can potentiate the bactericidal effects of different disinfection systems.

Despite the importance of catalase in protecting against oxidative stress and in infection, little is known about the function of catalase in $V$. vulnificus. Draft or complete genome sequences of several $V$. vulnificus strains have been reported (Chung et al., 2016; Efimov et al., 2015). These genomes generally contain one catalase. In the study presented here, recombinant, His-tagged catalase from $V$. vulnificus (CAT-Vv) was efficiently produced in a bacterial expression system and purified by immobilized metal affinity chromatography. The enzyme was biochemically characterized and mutants were used to analyze catalysis. The expression level of CAT- $V_{V}$ in $V$. vulnificus was also analyzed under different conditions.

\section{MATERIALS AND METHODS}

Bioinformatic analysis. Protein function was predicted using the NCBI Conserved Domain Search 
(Marchler-Bauer et al., 2015). Protein molecular weight and $\mathrm{pI}$ were calculated with the ExPASy Server (Gasteiger et al., 2005). Multiple protein sequence alignments were performed using the Clustal Omega program (Sievers et al., 2011). Unrooted phylogenetic trees were constructed with MEGA 6.0 using the Maximum Likelihood (NJ) method and bootstrap tests carried out with 1000 iterations (Tamura et al., 2013). Signal peptides were predicted using SignalP 4.0 (Petersen et al., 2011).

Protein expression and purification. $V$. vulnificus ATCC 43382 was cultured at $37^{\circ} \mathrm{C}$ in Luria-Bertani (LB) broth supplemented with $0.85 \% \mathrm{NaCl}$. DNA was recovered from harvested cell pellets using the Qiagen Genomic DNA Isolation kit (Valencia, CA, USA).

$V$. vulnificus genomic DNA was used as a template in a polymerase chain reaction (PCR), which amplified CAT-Vv (KTL38510) using the following oligonucleotide primers: forward, 5'-CGG GGATCC CAA ACG CT'T A CTC GTG A-3' and reverse, 5'-CCG CTCGAG TTA CAT CGA CGC CA-3'. The primers introduced BamHI and XhoI restriction sites (underlined), respectively. The PCR product and vector pET28(a) were digested with BamHI and XhoI, and ligated. The construct was sequenced by the Beijing Genomics Institute (BGI; Shenzhen, China) before transformation into Escherichia coli BL21 (DE3). E. coli BL21 (DE3) cells containing the $p E T 28-C A T-V v$ plasmid were cultured in $\mathrm{LB}$ broth at $37^{\circ} \mathrm{C}$. When $\mathrm{OD}_{600}$ reached $0.7,1 \mathrm{mM}$ isopropyl- $\beta$-D-thiogalactopyranoside (IPTG) was added to induce protein expression. The cells were cultured in the presence of IPTG for $4 \mathrm{~h}$ with shaking, at $37^{\circ} \mathrm{C}$, and then harvested and resuspended in a lysis buffer containing $50 \mathrm{mM}$ Tris (pH 7.5), $300 \mathrm{mM} \mathrm{NaCl}$, and $20 \mathrm{mM}$ imidazole. The cell suspension was sonicated at $30 \%$ power for $3 \mathrm{~min}$ and centrifuged at $25000 \times \mathrm{g}$ for $20 \mathrm{~min}$, and the supernatant was loaded onto a Ni-NTA column. After washing the column with lysis buffer, CAT-Vv was eluted using an imidazole gradient $(50-250 \mathrm{mM})$ in lysis buffer. Fractions containing catalase activity were pooled and dialyzed overnight against $50 \mathrm{mM}$ Tris buffer containing $100 \mathrm{mM} \mathrm{NaCl}$, pH 8.0. Purified CAT-Vv was separated by $12.5 \%$ sodium dodecyl sulfate polyacrylamide gel electrophoresis (SDSPAGE) and visualized by Coomassie Brilliant Blue staining. Protein concentrations were estimated using the Bradford method and bovine serum albumin as a standard (Bradford, 1976).

Site-directed mutagenesis of CAT-Vv. The primers used for mutagenesis were: V71A, forward, 5'-GAG CGA GTG GCT CAT GCT CGC-3'; reverse, 5'-GCG

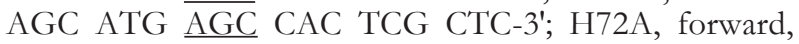
5'-CGA GTG GTG GCT GCT CGC GGT-3'; re-

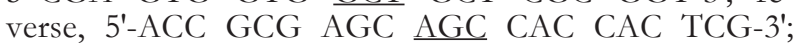
F158A, forward, 5'-TCG ATC AAG GCT CCT GAC ATG-3', reverse, 5'-CAT GTC AGG $\underline{\text { AGC CTT GAT }}$ CGA-3'; and Y353A, forward, 5'-T'TG TT'T GCT GCT GCC GAT ACG-3', reverse, 5'-CGT ATC GGC $\underline{\underline{\text { AGC }}}$ AGC AAA CAA-3' (the mutated sites are underlined). pET28a-CAT-Vv was used as the DNA template. The PCR reaction was performed for 18 cycles $\left(94^{\circ} \mathrm{C}\right.$ for $30 \mathrm{~s}, 55^{\circ} \mathrm{C}$ for $1 \mathrm{~min}$, and $68^{\circ} \mathrm{C}$ for $12 \mathrm{~min}$ ). After amplification, the PCR mixture was digested with DpnI and used to transform E. coli BL21 (DE3). All the mutants were confirmed by DNA sequencing by BGI. The mutant proteins (V71A, H72A, F158A, and Y353A) were purified by the same method as the wild-type protein (described above).

Gel filtration chromatography. Gel filtration chromatography was performed using a Superdex
$20010 / 30$ column (GE Healthcare) with a fast protein liquid chromatography system. The column was equilibrated with $50 \mathrm{mM}$ Tris, $100 \mathrm{mM} \mathrm{NaCl}$, pH 7.5. Protein standards included thyroglobulin $(660 \mathrm{kDa})$, ferritin $(440 \mathrm{kDa})$, catalase $(232 \mathrm{kDa})$, and ovalbumin (43 kDa).

Assays of CAT-Vv activity. Catalase activity was routinely determined spectrophotometrically at $35^{\circ} \mathrm{C}$ by monitoring the decrease in absorbance at $240 \mathrm{~nm}$

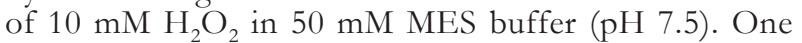
unit is defined as the amount of enzyme that catalyzed the oxidation of $1 \mu \mathrm{mol}$ of $\mathrm{H}_{2} \mathrm{O}_{2}$ min $^{-1}$ under the assay conditions used here.

To determine the influence of temperature on the enzymatic activity, reactions were performed at temperatures ranging from 10 to $50^{\circ} \mathrm{C}$. The influence of $\mathrm{pH}$ on CAT-Vv activity was determined using the protocol described above except that the Tris- $\mathrm{HCl}$ buffer was replaced with $50 \mathrm{mM}$ MES (pH 5.0-7.5), $50 \mathrm{mM}$ HEPES ( $\mathrm{pH} 8.0-8.5$ ), or $50 \mathrm{mM}$ glycine $(\mathrm{pH}$ 9.0-10.0); all of these assays were performed at the optimal temperature.

For kinetic studies, the initial velocities of the enzymatic reaction were examined by varying the concentration of $\mathrm{H}_{2} \mathrm{O}_{2}$ (from 1 to $100 \mathrm{mM}$ ) under the optimal conditions ( $\mathrm{pH} 7.5,35^{\circ} \mathrm{C}$, in $50 \mathrm{mM}$ MES buffer). Values of the Michaelis constant $\left(K_{\mathrm{m}}\right)$ and maximal velocity $\left(V_{\max }\right)$ were obtained by calculations using Sigma Plot software with a linear model. Every point was determined by three separate experiments.

Quantitative reverse transcription-PCR (RTqPCR). Culture of $V$. vulnificus was carried out as described above. Bacterial cells in the exponential phase were harvested by centrifugation and washed in an equal volume of phosphate-buffered saline (PBS, $\mathrm{pH}$ 7.0) with $0.85 \% \mathrm{NaCl}$. For the preparation of the low-salinity-adapted culture, the washed bacterial cells were incubated for $30 \mathrm{~min}$ in an equal volume of PBS containing $0.12 \% \mathrm{NaCl}$ plus 20 amino acids to prevent interference from nutrient starvation, as previously described (Wong \& Liu, 2008). To provide heat and oxidative stress, cells in the exponential phase were shocked by exposure to $42^{\circ} \mathrm{C}$ or $5 \mathrm{mM} \mathrm{H}_{2} \mathrm{O}_{2}$ for $30 \mathrm{~min}$. The cells were harvested and RNA was prepared with the TRIzol reagent (Invitrogen, CA). To ensure complete removal of any contaminating DNA, all RNA preparations were treated with DNase (Thermo Scientific Fermentas, Germany). RNA was quantified with a spectrophotometer and cDNA was synthesized with the Universal RiboClone cDNA Synthesis System (Promega, USA) per the manufacturer's protocols. Real-time PCR was performed with the CFX96 Real-Time PCR System (Bio-Rad, USA), using SYBR Green PCR Master Mix (Toyobo, Japan). The reaction products were serially diluted to find the appropriate concentration for real-time PCR analysis using the following primers: 5'-GGT ACA CGC TCA AAC GCT 'TA-3' and 5'-GCG GT'T ATC GAA T'TC TGG 'TT-3' (with amplification efficiency of 95.6\%). Reactions for detection of $16 \mathrm{~S}$ rRNA (LOSI01000001) levels were used for normalization between experimental samples and primers used were: 5'-GTC GTA GTC CGG ATT GGA GT-3' and 5'-GTA TTC ACC GTG GCA TTC TG-3' (with amplification efficiency 102.8\%). The relative fold changes were determined from the cycle threshold $\left(C_{\mathrm{T}}\right)$ values using the $\Delta \Delta C_{\mathrm{T}}$ method. The experiments were analyzed in three independent assays, with at least three technical replicates included in each PCR to ensure reproducibility. 


\section{RESULTS}

\section{In silico analysis of CAT-Vv}

CAT- $V_{v}$, which has not been previously characterized, was identified by homology and domain searches of the $V$. vulnificus genome using the NCBI Conserved Domain Search (Marchler-Bauer et al., 2015). The CAT-Vv ORF contains 1545 nucleotides and encodes a protein of 514 aa, with a theoretical pI of 8.69 and theoretical MW of $57.21 \mathrm{kDa}$ (http://web.expasy.org/compute_pi/). A phy- logenetic tree of proteins derived by the neighbor-joining method for CAT-Vv and catalases from archaea, bacteria, and eukaryotes is presented in Fig. 1. The tree places catalases from archaea in one cluster, while CAT-Vv and other catalases from bacteria were more closely related to the proteins from eukaryotes. Multiple sequence alignment had shown that the amino acid sequence of CAT- $V_{v}$ shows $66 \%$ and $46 \%$ identity to the catalases from Lipotes vexillifer and Lasius niger respectively, 62\% to that from Psendomonas syringe, and $52 \%$ to the Bacillus pumilus sequence. Amino acid sequence analysis indicated that CAT-Vv contains a hydrophobic stretch of about 20

A

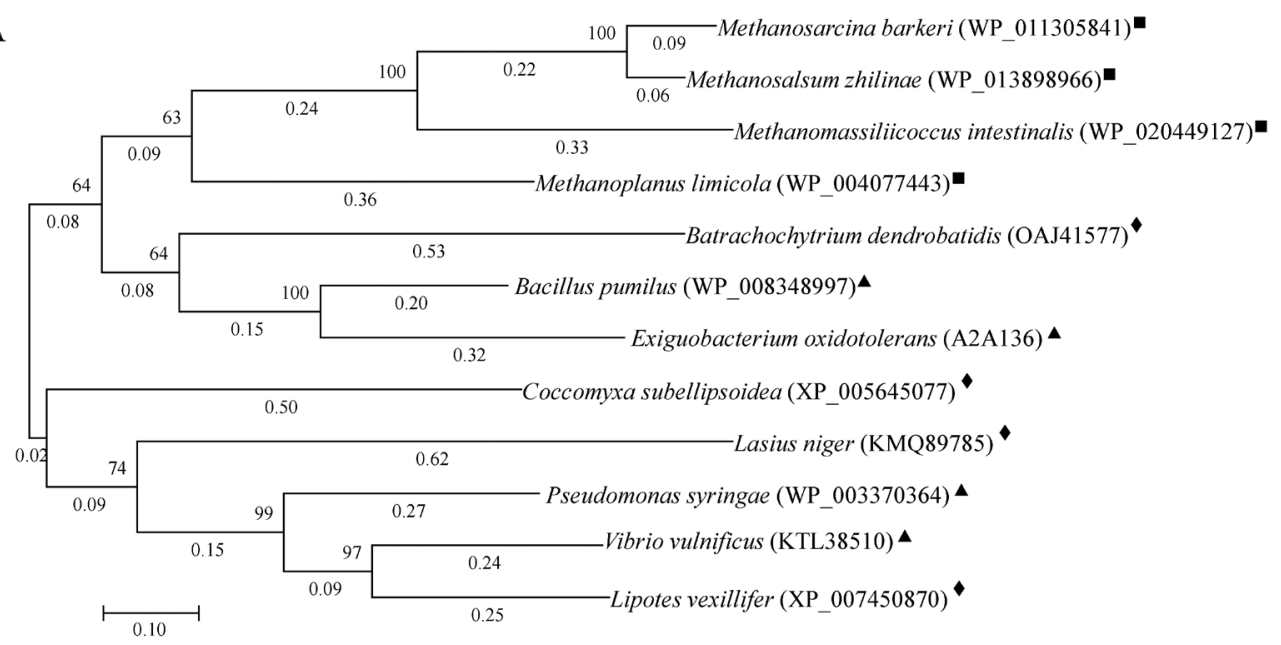

B

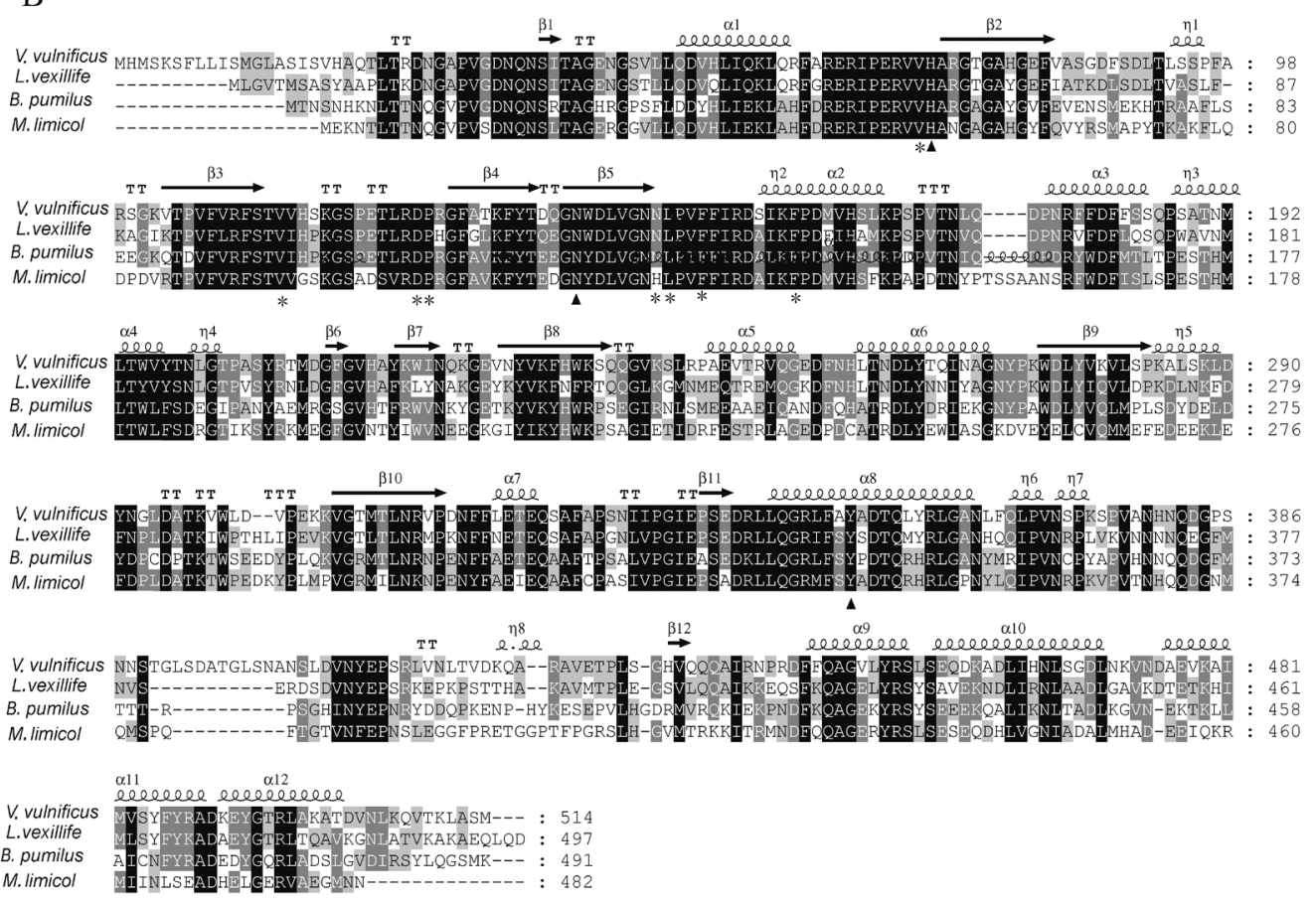

Figure 1. Phylogenetic and sequence analysis of CAT-Vv and other catalases.

(A) Molecular phylogenetic analysis of CATs from archaea (square), bacteria (triangle), and eukaryote (diamond) by Maximum Likelihood method generated using MEGA6. The percentage of trees in which the associated taxa clustered together is shown next to the branches. The percentage of replicate trees in which the associated taxa clustered together in the bootstrap test (1000 replicates) is shown next to the branches. The accession numbers of the proteins are indicated after the names of the species. (B) Sequence alignment of CAT-VV and other homologues. The residues involved in heme binding are indicated by triangles. The amino acid residues involved in the narrow channel are highlighted by stars. The predicted secondary structure is shown at the top of the alignment. a-Helices are represented as helices, $\beta$-strands are represented as arrows, $\beta$-turns are represented as " $T$," and 310-helices are represented as $\eta$. Signal peptide is labeled by the broken line. 
A

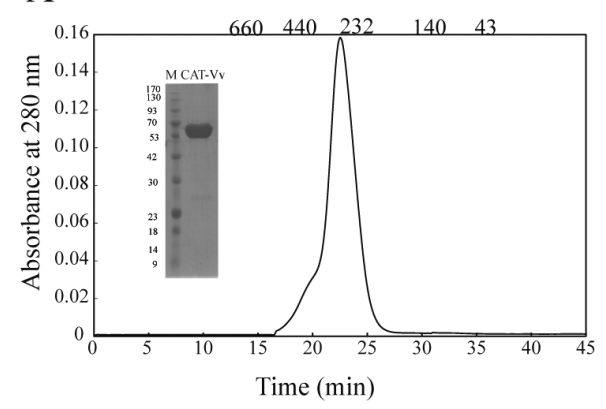

$\mathrm{B}$

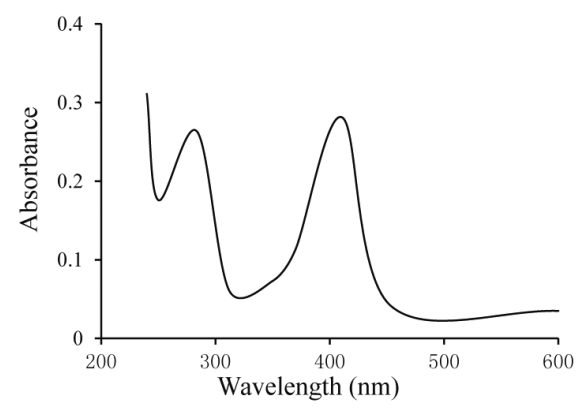

Figure 2. Purification and spectra of CAT-Vv.

(A) Purification and gel filtration chromatography of CAT-Vv. The insert shows the proteins that were electrophoresed on a $12.5 \%$ SDS-polyacrylamide gel and stained with Coomassie brilliant blue G-250. Lane M, protein marker; the molecular mass standards are indicated at the left. (B) UV/visible spectrum of CAT-Vv in $50 \mathrm{mM}$ MES buffer, $\mathrm{pH} 7.5$.

amino acids at the amino-terminus, which is most likely a signal sequence for secretion, while other homologs in bacteria lack this sequence. Multiple sequence alignment (Fig. 1B) revealed the presence of conserved residues responsible for heme binding, i.e., His72, Asn139, and Tyr353, as well as amino acids that form a channel connecting the active site of the enzyme to the external surface (Loewen et al., 2015; Rahi et al., 2011).

\section{Cloning, expression, and purification of CAT-Vv}

The CAT-Vv gene without the putative secretion signal at the $\mathrm{N}$-terminus was amplified from $V$. vulnificus genomic DNA using PCR and inserted into the expression vector pET28a which adds an N-terminal $6 \times$ Histag to the protein. Recombinant CAT-Vv was expressed in E. coli after $1 \mathrm{mM}$ IPTG induction (Fig. 2). The cells were collected by centrifugation and disrupted by sonication. The supernatants were applied to a nickel-affinity column and eluted using an imidazole gradient. Active catalase-containing fractions were pooled, and purified protein was visualized as a $58 \mathrm{kDa}$ protein by SDSPAGE (Fig. 2). Based on gel filtration chromatography analysis, CAT-Vv is a tetramer $(\sim 240 \mathrm{kDa})$ composed of $58 \mathrm{kDa}$ subunits. The UV/visible spectrum of the purified catalase with a Soret peak at $407 \mathrm{~nm}$ indicated the presence of a heme prosthetic group (Fig. 2).

\section{Optimal temperature and $\mathrm{pH}$ for activity}

The optimal temperature and $\mathrm{pH}$ of purified CAT$\mathrm{V}_{\mathrm{v}}$ were determined (Fig. 3). The recombinant enzyme is active above $10^{\circ} \mathrm{C}$, and then its activity increases with temperature. The highest catalytic activity toward $\mathrm{H}_{2} \mathrm{O}_{2}$ was observed at $35^{\circ} \mathrm{C}$. The relative activity of CAT-Vv increased with increasing $\mathrm{pH}$ and reached its highest val-
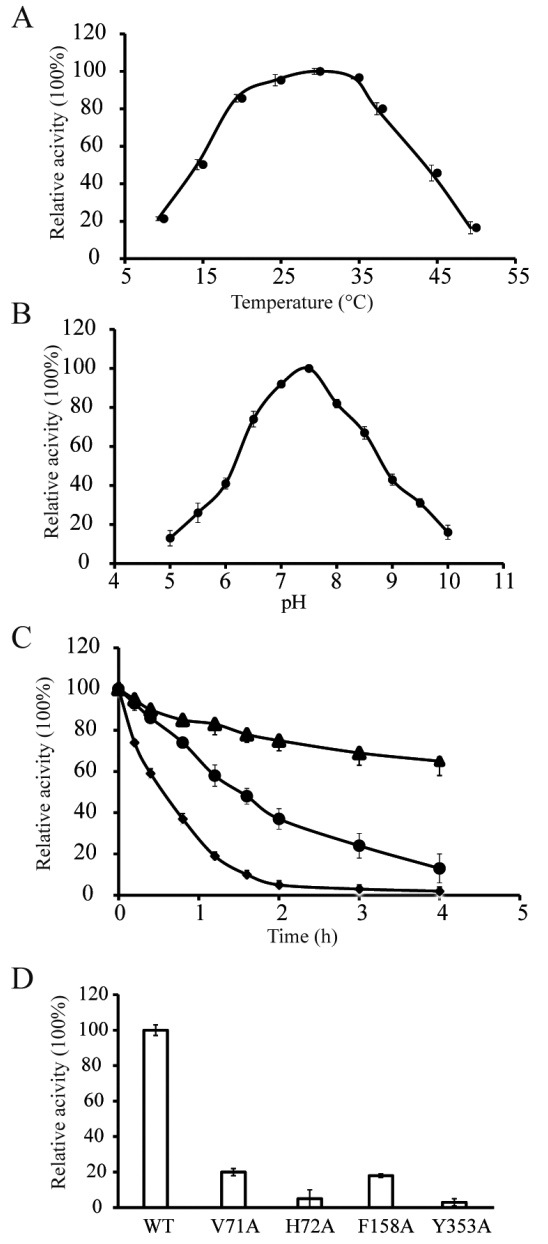

Figure 3. Enzyme activity assays of CAT-Vv.

(A) Optimal temperature of CAT- $\mathrm{V}_{\mathrm{v}}$ activity. (B) Optimal $\mathrm{pH}$ of CAT-Vv activity. Different buffers were used to obtain the different $\mathrm{pH}$ of solutions used in this assay. MES buffer was used for $\mathrm{pH} 5.0$ and 7.5; HEPES buffer was used for $\mathrm{pH} 8.0$ and 8.5; glycine buffer was used for $\mathrm{pH} 9.0$ and 10.0. (C) Effect of temperature on stability of recombinant CAT-Vv. The purified enzyme was pre-incubated at $37^{\circ} \mathrm{C}$ (triangle), $42^{\circ} \mathrm{C}$ (cycle) and $45^{\circ} \mathrm{C}$ (diamond) for different times and the residual activities of the enzymes were measured. (D) Relative activity of wild-type CAT-Vv, CAT-Vv-V71A, CAT-VvH72A, CAT-Vv-F158A, and CAT-Vv-Y353A. All experiments were performed in triplicate. The error bars mean the standard deviation of three measurements.

ue at $\mathrm{pH} 7.5$, then decreased to $60 \%$ of the maximum at $\mathrm{pH} 8.5$.

\section{Thermostability of CAT-Vv}

To examine the thermostability of CAT- $\mathrm{Vv}$, the enzyme was incubated at $37^{\circ} \mathrm{C}, 42^{\circ} \mathrm{C}$, and $45^{\circ} \mathrm{C}$ at $\mathrm{pH}$ 7.5 in MES buffer. As Fig. 3 shows, the relative activity gradually reduced with increasing temperature or with extension of incubation time. At $37^{\circ} \mathrm{C}$, the relative activity of CAT- $\mathrm{V}_{\mathrm{v}}$ remained $80 \%$ after $2 \mathrm{~h}$ and $70 \%$ after $4 \mathrm{~h}$. The relative activity reduced to $40 \%$ after $40 \mathrm{~min}$ at $45^{\circ} \mathrm{C}$.

\section{Effects of point mutations on enzymatic activity}

The X-ray crystal structure of catalase revealed that the enzyme forms a hydrophobic channel that provides access from the protein surface to the active site; the channels of catalase are $25-55 \AA$ from the protein surface to the heme (Hara et al., 2007). Multiple sequence 


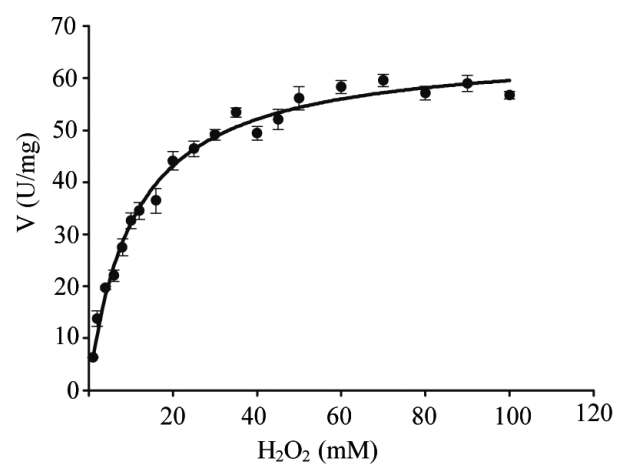

Figure 4. Kinetics assay of CAT-Vv.

The velocity data obtained with the increase of substrate concentrations were fitted to the Michaelis-Menten equation by non-linear regression calculations.

alignment had shown that in CAT-Vv, His72 and Tyr353 may bind heme, while Val71 and Phe158 may be involved in the channel formation (Fig. 1). To confirm the function of these amino acids, they were individually mutated to Ala. The mutant proteins were expressed and purified and the activities were measured (Fig. 3). The mutants in heme-binding residues ( $\mathrm{H} 72 \mathrm{~A}$ and $\mathrm{Y} 353 \mathrm{~A}$ ) had barely detectable catalase activity. The activity toward $\mathrm{H}_{2} \mathrm{O}_{2}$ of the channel point mutants (V71A and F158A) was approximately $20 \%$ of that of wild-type CAT-Vv. These experimental findings confirmed that heme binding is very important for catalysis.

\section{Enzyme kinetics}

The kinetics of recombinant wild-type CAT-Vv were analyzed using $\mathrm{H}_{2} \mathrm{O}_{2}$ as a substrate (Fig. 4). The reaction was performed in MES buffer $(\mathrm{pH} 7.5)$ at $35^{\circ} \mathrm{C}$ with $\mathrm{H}_{2} \mathrm{O}_{2}$ concentrations ranging from 1 to $100 \mathrm{mM}$. The Michaelis-Menten equation was used to calculate the kinetic parameters. The $K_{\mathrm{m}}$ and $V_{\mathrm{max}}$ values for CAT-Vv were found to be $10.5 \pm 0.7 \mathrm{mM}$ and $65.8 \pm 1.2 \mathrm{U} / \mathrm{mg}$, respectively.

\section{Expression profile of the CAT-Vv gene under stress conditions}

Considering previous reports that the expression of catalase genes can be induced by various stresses, we used qRT-PCR to examine expression of the CAT-Vv gene in $V$. vulnificus in response to three different abiotic stresses. RNA was isolated from $V$. vulnificus cells grown under stress. Figure 5 shows the relative expression patterns of CAT-Vv. Under low-salinity or heat treatment, the transcript level of CAT-Vv had shown an obvious increase relative to unstressed cells and peaked at $15 \mathrm{~min}$, after which the expression level decreased. Under oxidative stress treatment, the transcript level of $C A T-V v$ reached a peak at $5 \mathrm{~min}$. These results suggest that $C A T-V v$ plays a role in defense against various stresses.

\section{DISCUSSION}

Catalase is found in plants, animals and microbes (Sooch et al., 2014). V. vulnificus, an opportunistic human pathogen, is responsible for the overwhelming majority of reported seafood-related deaths Jones \& Oliver, 2009). In this study, we cloned, expressed, and biochemically characterized a catalase from $V$. vulnificus (CAT-Vv)
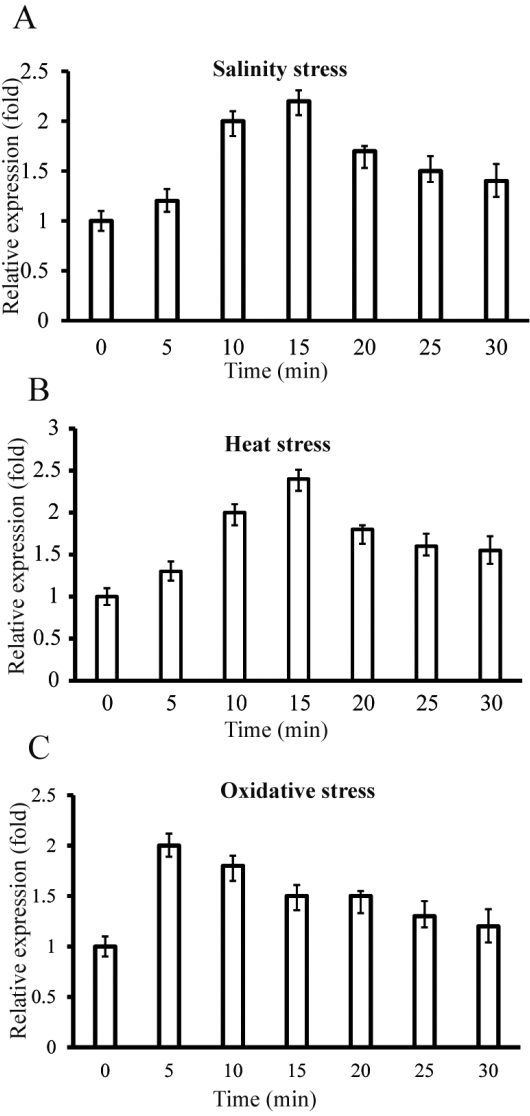

Figure 5. Expression level of $C A T-V_{V}$ gene under low salinity (A), heat (B), and oxidative (C) stresses.

The culture and treatment of $V$. vulnificus were described as in "Materials and methods." The mRNA relative quantity of CAT-VV from $V$. vulnificus cells treated by different stresses was measured by RT-qPCR and indicated as fold difference from the value of the untreated cells, which was taken as 1. Error bars indicate the standard deviations from three independent experiments.

for the first time. The recombinant enzyme, with a subunit molecular mass of $58 \mathrm{kDa}$, exists as a tetramer with a native molecular mass of $240 \mathrm{kDa}$. Activity assays of the wild-type and mutant proteins had shown that hemebinding residues are critical for activity. The native transcription level of $C A T-V v$ was upregulated by salinity, heat, and oxidative stress. Considering the importance of catalase in protecting $V$. vulnificus, we propose that CAT-Vv could be a potential target to control the growth of $V$. vulnificus.

Previous studies had shown that monofunctional catalases could be divided into three distinct clades based on phylogenetic analysis of the conserved core region (Klotz et al., 1997; Nicholls et al., 2000). Catalases in clade 1 are mainly from plants but also include catalases of algal and bacterial origin. Clade 2 catalases are proteins with a large-subunit, from bacteria, archaea, and fungi. This clade of catalases shows a strong tolerance to denaturation by proteolysis and heat (Chelikani et al., 2004). Clade 3 catalases are from bacteria, archaea, and eukaryotes. There is no clear functional difference between clade 1 and clade 3 catalases (Hara et al., 2007). The calculated molecular mass of CAT-Vv $(56,487.7 \mathrm{Da})$ is similar to those of clade 1 and 3 catalases (55-69 kDa). Sequence alignments and phylogenetic analysis indicated that CAT-Vv exhibits a high degree of similarity with clade 1 catalases (e.g., catalases from P. syringe and B. pumilus, Fig. 1) (Carpena et al., 2003; Loewen et al., 2015). Inter- 
estingly, CAT-Vv contains a predicted N-terminal signal peptide directing the secretion of the enzyme which is absent from the catalases from $P$. syringe and B. pumilus (Fig. 1).

The distribution of $V$. vulnificus in the environment is positively correlated with salinity (20 to $25 \mathrm{ppm}$ ) (Randa et al., 2004). Fresh water is often used to wash seafood that harbors $V$. vulnificus. Thus, low salinity is a common stressor for this pathogenic bacterium in both natural and food-processing environments (Wong \& Liu, 2008). RpoS, the sigma factor of $V$. vulnificus, plays an active role in low salinity adaptation, as well as resistance to diverse environmental stresses including exposure to hydrogen peroxide and acidic conditions (Tan et al., 2010). VvhA, a virulence factor of $V$. vulnificus, was also reported to be involved in osmoprotection and/or cold shock response (Smith \& Oliver, 2006). Catalase is a ubiquitous enzyme that destroys hydrogen peroxide formed during oxidative stress. In the study presented here, our results demonstrate that $C A T-V v$ is upregulated by low salinity, heat, and oxidative stress. Pezzoni and coworkers (2014) reported that an extracellular catalase is an essential factor in the resistance of $P$. aeruginosa biofilms to UVA exposure. In addition, degradation of the host-produced $\mathrm{H}_{2} \mathrm{O}_{2}$ by a secreted catalase is considered essential to the success of infection (Tanabe et al., 2009). Based on this evidence, we propose that CAT- $\mathrm{V}_{\mathrm{v}}$ plays crucial roles in the survival, antioxidant defense, and infectivity of $V$. vulnificus.

\section{Conflict of interest}

The authors have declared no conflict of interest.

\section{Funding}

This study was supported by a startup funding (8804/880415014) from Shenyang Agricultural University.

\section{REFERENCES}

Anjum NA, Sharma P, Gill SS, Hasanuzzaman M, Khan EA, Kachhap K, Mohamed AA, Thangavel P, Devi GD, Vasudhevan P, Sofo A, Khan NA, Misra AN, Lukatkin AS, Singh HP, Pereira E, Tuteja $\mathrm{N}$ (2016) Catalase and ascorbate peroxidase-representative $\mathrm{H}_{2} \mathrm{O}_{2}$ detoxifying heme enzymes in plants. Environ Sci Pollut Res Int 23: 19002-19029. doi: 10.1007/s11356-016-7309-6

Bradford MM (1976) A rapid and sensitive method for the quantitation of microgram quantities of protein utilizing the principle of proteindye binding. Anal Biochem 72: 248-254

Carpena X, Soriano M, Klotz MG, Duckworth HW, Donald LJ, MelikAdamyan W, Fita I, Loewen PC (2003) Structure of the Clade 1 catalase, $\mathrm{CatF}$ of Pseudomonas syringae, at $1.8 \AA$ resolution. Proteins 50: 423-436. doi: 10.1002/prot.10284

Chelikani P, Fita I, Loewen PC (2004) Diversity of structures and properties among catalases. Cell Mol Life Sci 61: 192-208. Doi: 10.1007/s00018-003-3206-5

Chung HY, Kim YT, Kim S, Na EJ, Ku HJ, Lee KH, Heo ST, Ryu S, Kim H, Choi SH, Lee JH (2016) Complete genome sequence of Vibrio vulnificus FORC_017 isolated from a patient with a hemorrhagic rash after consuming raw dotted gizzard shad. Gut Pathog 8: 22. Doi: 10.1186/s13099-016-0104-6

Deisseroth A, Dounce AL (1970) Catalase: Physical and chemical properties, mechanism of catalysis, and physiological role. Physiological reviews 50: 319-375

Efimov V, Danin-Poleg Y, Green SJ, Elgavish S, Kashi Y (2015) Draft genome sequence of the pathogenic bacterium Vibrio vulnificus V252 biotype 1, isolated in Israel. Genome Announc 3: e01182-15. doi: 10.1128/genomeA.01182-15

Foyer CH, Noctor G (2000) Oxygen processing in photosynthesis: regulation and signalling. New Phytologist 146: 359-388. doi: 10.1046/j.1469-8137.2000.00667.x

Gasteiger E, Hoogland C, Gattiker A, Duvaud Se, Wilkins MR, Appel RD, Bairoch A (2005) Protein identification and analysis tools on the ExPASy server. In The Proteomics Protocols Handbook, Walker JM ed, pp 571-607. Humana Press. New York

Hara I, Ichise N, Kojima K, Kondo H, Ohgiya S, Matsuyama H, Yumoto I (2007) Relationship between the size of the bottleneck $15 \AA$ from iron in the main channel and the reactivity of catalase corresponding to the molecular size of substrates. Biochemistry 46: 11-22. doi: $10.1021 / \mathrm{bi061519w}$

Jones MK, Oliver JD (2009) Vibrio vulnificus: Disease and Pathogenesis. Infect Immun 77: 1723-1733. doi: 10.1128/IAI.01046-08

Kitamura C, Yamauchi Y, Yamaguchi T, Aida Y, Ito K, Ishizawa Y, Saitoh K, Kasai T, Ohnishi M (2016) Successful treatment of a case of necrotizing fasciitis due to Vibrio vulnificus in a cold climate in Japan. Intern Med 55: 1007-1010. doi: 10.2169/internalmedicine. 55.5231

Klotz MG, Klassen GR, Loewen PC (1997) Phylogenetic relationships among prokaryotic and eukaryotic catalases. Mol Biol Evol 14: 951958

Lee BC, Choi SH, Kim TS (2008) Vibrio vulnificus RTX toxin plays an important role in the apoptotic death of human intestinal epithelial cells exposed to Vibrio vulnificus. Microbes Infect 10: 1504-1513. doi: 10.1016/j.micinf.2008.09.006

Lee BC, Kim MS, Choi SH, Kim KY, Kim TS (2009) In vitro and in vivo antimicrobial activity of water-soluble chitosan oligosaccharides against Vibrio vulnificus. Int J Mol Med 24: 327-333. doi: 10.3892/ ijmm_00000236

Loewen PC, Villanueva J, Switala J, Donald LJ, Ivancich A (2015) Unprecedented access of phenolic substrates to the heme active site of a catalase: substrate binding and peroxidase-like reactivity of Bacillus pumilus catalase monitored by X-ray crystallography and EPR spectroscopy. Proteins 83: 853-866. doi: 10.1002/prot.24777

Lushchak VI (2014) Free radicals, reactive oxygen species, oxidative stresses and its classifications. Chem Biol Interact 224: 164-175. doi: 10.1016/j.cbi.2014.10.016

Mahmoud BSM (2009) Reduction of Vibrio vulnificus in pure culture, half shell and whole shell oysters (Crassostrea virginica) by X-ray. Int J Food Microbiol 130: 135-139. doi: 10.1016/j.ijfoodmicro.2009.01.023

Melody K, Senevirathne R, Janes M, Jaykus LA, Supan J (2008) Effectiveness of icing as a postharvest treatment for control of Vibrio vulnificus and Vibrio parahaemolyticus in the eastern oyster (Crassostrea virginica). J Food Prot 71: 1475-1480

Marchler-Bauer A, Derbyshire MK, Gonzales NR, Lu S, Chitsaz F, Geer LY, Geer RC, He J, Gwadz M, Hurwitz DI, Lanczycki CJ, Lu F, Marchler GH, Song JS, Thanki N, Wang Z, Yamashita RA, Zhang D, Zheng C, Bryant SH (2015) CDD: NCBI's conserved domain database. Nucleic Acids Res 43: D222-D226. doi: 10.1093/nar/ gku1221

Melody K, Senevirathne R, Janes M, Jaykus LA, Supan J (2008) Effectiveness of icing as a postharvest treatment for control of Vibrio vulnificus and Vibrio parabaemolyticus in the eastern oyster (Crassostrea virginica). J Food Prot 71: 1475-1480

Motes ML, DePaola A, Cook DW, Veazey JE, Hunsucker JC, Garthright WE, Blodgett RJ, Chirtel SJ (1998) Influence of water temperature and salinity on Vibrio vulnificus in northern gulf and atlantic coast oysters (Crassostrea virginica). Appl Environ Microbiol 64: 14591465

Mullineaux PM, Karpinski S, Baker NR (2006) Spatial dependence for hydrogen peroxide-directed signaling in light-stressed plants. Plant Physiol 141: 346-350. doi: 10.1104/pp.106.078162

Nakamura K, Kanno T, Mokudai T, Iwasawa A, Niwano Y, Kohno M (2012) Microbial resistance in relation to catalase activity to oxidative stress induced by photolysis of hydrogen peroxide. Microbiol Immunol 56: 48-55. doi: 10.1111/j.1348-0421.2011.00400.x

Nicholls P, Fita I, Loewen PC (2000) Enzymology and structure of catalases. In Advances in Inorganic Chemistry, vol 51, pp 51-106. Academic Press. doi: 10.1016/S0898-8838(00)51001-0

Oliver JD (2015) The biology of Vibrio vulnificus. Microbiol Spectr 3: 3. doi: 10.1128/microbiolspec.VE-0001-2014.

Pajuelo D, Hernandez-Cabanyero C, Sanjuan E, Lee CT, Silva-Hernandez FX, Hor LI, MacKenzie S, Amaro C (2016) Iron and Fur in the life cycle of the zoonotic pathogen Vibrio vulnificus. Environ $\mathrm{Mi}$ crobiol 18: 4005-4022. doi: 10.1111/1462-2920.13424

Pezzoni M, Pizarro RA, Costa CS (2014) Protective role of extracellular catalase (KatA) against UVA radiation in Pseudomonas aeruginosa biofilms. J Photochem Photobiol B 131: 53-64. doi: 10.1016/j.jphotobiol.2014.01.005

Rahi A, Rehan M, Garg R, Tripathi D, Lynn AM, Bhatnagar R (2011) Enzymatic characterization of Catalase from Bacillus anthracis and prediction of critical residues using information theoretic measure of Relative Entropy. Biochem Biophys Res Commun 411: 88-95. doi: 10.1016/j.bbrc.2011.06.099

Ramos RJ, Miotto M, Squella FJL, Cirolini A, Ferreira JF, Vieira CRW (2012) Depuration of oysters (Crassostrea gigas) contaminated with Vibrio parahaemolyticus and Vibrio vulnificus with UV light and chlorinated seawater. J Food Prot 75: 1501-1506. doi: 10.4315/0362-028X. JFP-11-467 
Randa MA, Polz MF, Lim E (2004) Effects of temperature and salinity on Vibrio vulnificus population dynamics as assessed by quantitative PCR. Appl Environ Microbiol 70: 5469-5476. doi: 10.1128/ AEM.70.9.5469-5476.2004

Sievers F, Wilm A, Dineen D, Gibson TJ, Karplus K, Li W, Lopez R, McWilliam H, Remmert M, Soding J, Thompson JD, Higgins DG (2011) Fast, scalable generation of high-quality protein multiple sequence alignments using Clustal Omega. Mol Syst Biol 7: 539. doi: $10.1038 / \mathrm{msb} .2011 .75$

Smith B, Oliver JD (2006) In situ and in vitro gene expression by $V i$ brio vulnificus during entry into, persistence within, and resuscitation from the viable but nonculturable state. Appl Environ Microbiol 72: 1445-1451. doi: 10.1128/AEM.72.2.1445-1451.2006

Sooch BS, Kauldhar BS, Puri M (2014) Recent insights into microbial catalases: isolation, production and purification. Biotechnol Adv 32 . 1429-1447. doi: 10.1016/j.biotechadv.2014.09.003

Strom MS, Paranjpye RN (2000) Epidemiology and pathogenesis of Vibrio vulnificus. Microbes Infect 2: 177-188
Tamura K, Stecher G, Peterson D, Filipski A, Kumar S (2013) MEGA6: Molecular Evolutionary Genetics Analysis Version 6.0. Mol Biol Evol 30: 2725-2729. doi: 10.1093/molbev/mst197

Tan HJ, Liu SH, Oliver JD, Wong HC (2010a) Role of RpoS in the susceptibility of low salinity-adapted Vibrio vulnificus to environmental stresses. Int J Food Microbiol 137: 137-142. doi: 10.1016/j.ijfoodmicro.2009.12.006

Tanabe S, Nishizawa Y, Minami E (2009) Effects of catalase on the accumulation of $\mathrm{H} 2 \mathrm{O} 2$ in rice cells inoculated with rice blast fungus, Magnaporthe oryzae. Physiol Plant 137: 148-154. doi: 10.1111/j.13993054.2009.01272.x

Wong HC, Liu SH (2008) Characterization of the low-salinity stress in Vibrio vulnificus. J Food Prot 71: 416-419. doi: 10.4315/0362-028X. JFP-11-321

Ye M, Huang Y, Gurtler JB, Niemira BA, Sites JE, Chen H (2013) Effects of pre- or post-processing storage conditions on high-hydrostatic pressure inactivation of Vibrio parabaemolyticus and V. vulnificus in oysters. Int J Food Microbiol 163: 146-152. doi: 10.1016/j. ijfoodmicro.2013.02.019 